\title{
GENDER DIFFERENCE OF SUBJECTIVE RESPONSES TO WHOLE-BODY VIBRATION UNDER STANDING POSTURE
}

\author{
*Nobuyuki Shibata, Kazuma Ishimatsu and Setsuo Maeda \\ National Institute of Occupational Safety and Health, Kawasaki, Japan
}

Introduction

Passengers in public transportation such as bus and railway are often exposed to whole-body vibration under standing posture. Also regardless of the gender difference, people use the public transportation in their daily life. Although a method of measurement and evaluation of whole-body vibration (WBV) in relation to human health and comfort has been specified in the international standard ISO2631-1 [1], the subjective scale for ride comfort shown in this standard has been based on poor data on female subjects under standing posture.

The main aim of this study was to examine gender difference in subjective response to WBV with different vibration axes under standing posture.

\section{Methods}

The experiments were performed with totally twenty four healthy subjects in twenties, twelve males and twelve females with mean ages of 22.3 and 21.6 years old, respectively. None of the subjects have been exposed to high levels or long periods of WBV occupationally or in their leisure time activities. The experiments were approved by the Research Ethics Committee of Japan NIOSH. All the subjects underwent an explanation of the test procedure and gave their written informed consent to participate in this study.

Signals prepared for WBV stimuli were three ISO frequency-weighted r.m.s. acceleration magnitudes of $0.2,0.4$, and $0.8 \mathrm{~m} / \mathrm{s}^{2}$, each of which had a frequency range of $1-100 \mathrm{~Hz}$ with a constant power spectrum density. A series of 27 vibration stimuli (three times for three acceleration magnitudes for each direction), each of which was ordered randomly, were applied to the subject standing upright on the platform of a multi-axis vibration system installed in the Japan NIOSH. All the vibration stimuli had a duration time of seven seconds with a two-second pause between adjacent stimuli.

The subjects were asked to respond orally to each vibration stimulus by selecting a certain category number, corresponding to a degree of discomfort they felt, from the five comfort evaluation categories. Subjective scale was obtained from the questionnaire data by using the category judgment method [2].

\section{Results and Discussion}

Regardless of vibration axis, the male subjects responded severely to vibration stimuli below a level of category 4 (Uncomfortable) compared to the female subjects. Under standing posture the subjects, regardless of the gender difference, responded more 
severely to vertical vibration than to fore-and-aft and lateral vibration. Our results suggest that the gender difference between subjective responses to WBV is highly affected by vibration axis and by vibration acceleration magnitude. The data obtained in this study can be contributed as fundamental data to update the present standard, ISO 2631-1.

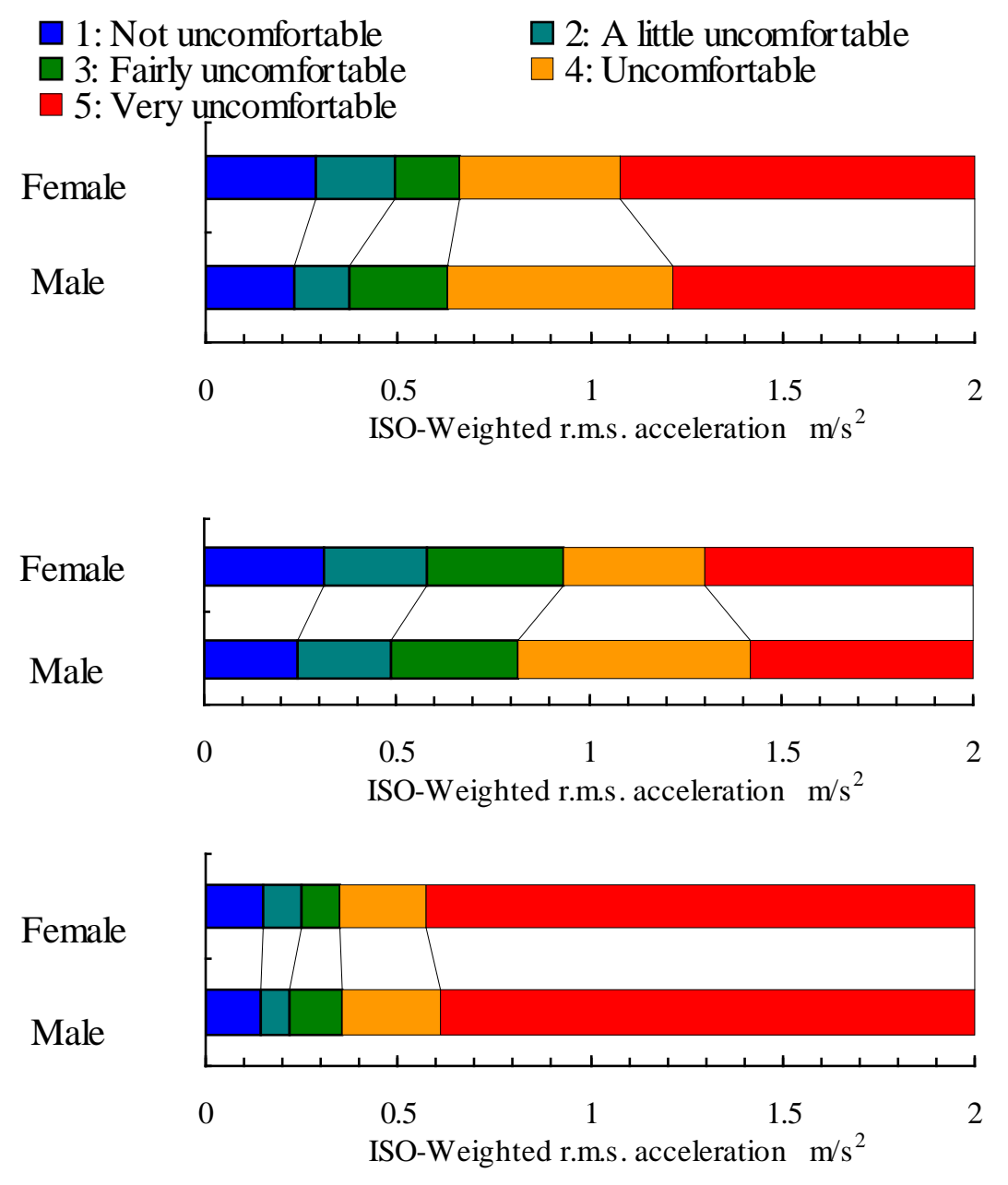

(a)

(b)

(c)

Figure 1 Subjective scales for female and male in (a) fore-and-aft (b) lateral and (c) vertical axis vibration.

\section{References}

[1] Mechanical vibration and shock -Evaluation of human exposure to whole-body vibration- Part 1: General requirements, International Standard ISO 2631-1: 1997 (International Organization for Standardization, Geneva, Switzerland, 1997).

[2] Guilford JP. Psychometric methods. McGraw-Hill. New York, (1954). 